\title{
Definitions and methods of measuring and reporting on injurious falls in randomised controlled fall prevention trials: a systematic review
}

Michael Schwenk ${ }^{1 *+}$, Andreas Lauenroth ${ }^{2 \dagger}$, Christian Stock ${ }^{2,3}$, Raquel Rodriguez Moreno ${ }^{1}$, Peter Oster ${ }^{1}$, Gretl McHugh ${ }^{4}$, Chris Todd ${ }^{4}$ and Klaus Hauer ${ }^{1}$

\begin{abstract}
Background: The standardisation of the assessment methodology and case definition represents a major precondition for the comparison of study results and the conduction of meta-analyses. International guidelines provide recommendations for the standardisation of falls methodology; however, injurious falls have not been targeted. The aim of the present article was to review systematically the range of case definitions and methods used to measure and report on injurious falls in randomised controlled trials (RCTs) on fall prevention.

Methods: An electronic literature search of selected comprehensive databases was performed to identify injurious falls definitions in published trials. Inclusion criteria were: RCTs on falls prevention published in English, study population $\geq 65$ years, definition of injurious falls as a study endpoint by using the terms "injuries" and "falls".

Results: The search yielded 2089 articles, 2048 were excluded according to defined inclusion criteria. Forty-one articles were included. The systematic analysis of the methodology applied in RCTs disclosed substantial variations in the definition and methods used to measure and document injurious falls. The limited standardisation hampered comparability of study results. Our results also highlight that studies which used a similar, standardised definition of injurious falls showed comparable outcomes.

Conclusions: No standard for defining, measuring, and documenting injurious falls could be identified among published RCTs. A standardised injurious falls definition enhances the comparability of study results as demonstrated by a subgroup of RCTs used a similar definition. Recommendations for standardising the methodology are given in the present review.
\end{abstract}

Keywords: Systematic review, Injurious falls, Elderly, Fall-related outcomes, Fall prevention trials

\section{Background}

At least $30 \%$ of persons aged over 65 years experience one or more falls each year $[1,2]$ and this proportion increases to $40 \%$ after age of 75 [3]. Both the incidence of falls and the severity of complications stemming from a fall increase with age, level of disability, and extent of

\footnotetext{
* Correspondence: mschwenk@bethanien-heidelberg.de

+ Contributed equally

'Department of Geriatric Research, AGAPLESION Bethanien-Hospital/Geriatric Center at the University of Heidelberg, Rohrbacherstr.149, Heidelberg 69126, Germany

Full list of author information is available at the end of the article
}

functional impairment $[4,5]$. Falls are a major health problem in older adults, causing fall-related sequelae such as fractures, head injuries, and post-fall anxiety [6-11]. Older adults are hospitalised for fall-related injuries five times more often than they are for injuries from other causes [6]. The costs of injurious falls substantially burden health care systems [12].

The prevention of falls in older people is an important health target in many countries [13,14] and numerous studies have been published to identify appropriate intervention strategies [7,15-18]. Systematic reviews of RCTs of fall prevention interventions demonstrate that

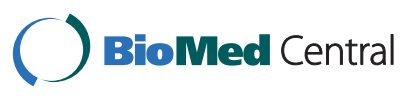


the risk of falling can effectively be reduced [7,15-18]. However, sound evidence for the reduction of injurious falls remains limited [13,16,19-23]. Evidence for the prevention of fall-related injuries has been shown in controlled trials [21,23,24] but so far no randomised controlled trial (RCT) evidence of effectiveness is available [14]. Most RCTs are underpowered to detect a significant reduction in injurious fall rates owing to the relative infrequency of injurious fall events $[19,22,25]$ and the extremely large sample sizes required to achieve adequate statistical power.

However, severe falls and their resultant injuries have a high impact on medical sequelae [26], quality of life [27] and cost to health services [12,28]. Reducing injurious falls should therefore represent a major goal of fall prevention policy [13] and necessarily be benchmarked by a high level of evidence [29].

Because of the high cost of performing RCTs to evaluate the effects of specific fall prevention strategies on injurious falls, the combination of trial data in a metaanalysis is an attractive option but is dependent on the comparability of interventions and outcome measures. A substantial precondition for high-quality meta-analysis is a standardised methodology [30] characterised by consistency in defining injurious falls and methods of collecting and documenting falls data. However, existing international guidelines for the conduct of fall prevention trials [13] do not provide sufficient recommendations for the standardisation of injurious falls methodology. A systematic literature review on definitions and methods of measuring falls in randomised controlled fall prevention trials [31] provided a methodological consensus for defining and collecting falls, but not injurious falls, data.

Limited standardisation in defining injuries has repeatedly been reported as a serious methodological pitfall when comparing study outcomes [13,31] and has been identified as a substantial methodological challenge for future studies [32]. Standardised methodology has therefore been repeatedly requested $[13,33]$. However, to our knowledge, there is no systematic review focusing on injurious falls methodology in fall prevention trials aiming to develop a methodological consensus for future studies.

We therefore conducted a systematic review of definitions and methods of measuring and reporting on injurious falls in randomised controlled fall prevention trials. The aim of this study was to collect and compare definitions of injurious falls and associated assessment methods and develop an outcome data set for use in future fall prevention trials including injurious falls as a study endpoint.

\section{Methods}

This review is part of a series of reviews on behalf of the Prevention of Falls Network Europe (ProFaNE) which evaluate methodology in RCTs of fall prevention interventions in older adults. Inclusion criteria were (1) RCTs of fall prevention interventions published in English, (2) target population $\geq 65$ years, (3) definition of injurious falls as a study endpoint by using the terms "injury" and "falls".

\section{Search strategy}

An electronic literature search was performed through Ovid MEDLINE, Ovid EMBASE, CINAHL, PsycINFO, the Cochrane library and GeroLit (all from inception until $16^{\text {th }}$ of July 2011). The following search strategy was applied: ("Accidental Falls/" OR "fall.mp." (mp)) AND ("Accident Prevention/" OR "prevent\$.mp." OR "prophyl\$.mp.") AND ("clinical trials/" OR “clinical trial. mp" OR "randomised.mp" OR "randomized.mp" OR "randomly.mp"). Reference lists of included studies and of related reviews were searched for potentially eligible studies. Moreover researchers in the field were contacted and asked for additional trial reports.

\section{Study selection and data extraction}

Study selection was performed by three independent reviewers (AL, CS, GM) and disagreements were resolved by a fourth party $(\mathrm{KH})$ [34]. Titles and abstracts of retrieved references were screened for inclusion and full texts of potential articles were analysed for meeting the inclusion criteria.

Data extraction was performed by three independent reviewers using a standardised form (AL, MS, GM). Definitions of injurious falls and methods used to record injurious falls were extracted from papers and classified according to subcategories. Frequencies of the definitions and methods used were documented as absolute (number of articles $=\mathrm{n}$ ) and relative (number of articles using a specific definition or method/number of articles included in the review *100) values. Where possible, the number of falls and injurious falls was extracted from the papers and the proportion of injurious falls to all falls (number of injurious falls/number of all falls * 100) was calculated. Relationship between the type of injurious fall definition used in studies and the proportion of injurious falls reported was evaluated by descriptive analysis. To measure the variability of the proportion of injurious falls between studies, the coefficient of variation [35] [(CV = (standard deviation/mean) $\times 100)$ ] was calculated. The CV expresses the percentage variation between articles, thereby providing an indicator of agreement with respect to the proportion of 
injurious falls. Higher CVs indicate less agreement between studies.

\section{Results}

\section{Selection of articles}

The search yielded 2089 articles, 1778 were excluded on initial screening as not fulfilling entry criteria, thus 311 were potentially appropriate for inclusion in the review (Figure 1). Of these 311 papers, 270 were excluded, because on closer inspection they did not provide a definition of injurious falls or did not report on injurious falls or did not meet other inclusion criteria. Forty-one articles were finally included in the review.

\section{Injurious fall definition}

Definitions of injurious falls used in the articles included in this review are shown in Table 1 . There was considerable heterogeneity in defining injurious falls and no definition stood out as the gold standard. Three main categories of definitions were found: (1) definitions based on symptoms ( $\mathrm{n}=16,39 \%)$; (2) combined definitions based on symptoms and healthcare use $(\mathrm{n}=19,46 \%)$; (3) definitions based on healthcare use $(n=6,15 \%)$. The most frequent type of definition that has been used similarly in different articles $(n=6,15 \%)$ originates from a study by Campbell et al. [36]. This definition sub-classifies falls according to severity (serious, moderate) by using both symptomatic features (fractures, bruising, sprains, cuts, abrasions, reduction in physical function) and healthcare use (hospital, any wounds needed stitches, medical help). Referencing for this definition was inconsistent as some papers gave other primary sources [37] and some no reference at all $[36,38,39]$.

Four articles (10\%) used the definition of the Frailty and Injuries Cooperative Studies of Intervention Techniques (FICSIT) collaboration, with two studies [56,57] using the original definition and two using a modified version ("head injuries with altered consciousness" instead of "head injuries requiring hospitalisation" [58]; "severe sprains" instead of "sprains" [59]). Three articles (7\%) defined injurious falls according to the Abbreviated Injury Scale (AIS) [77] using a severity score based on medical symptoms (ranging from low-level injuries that did not require medical attention to high-level injuries which necessitated medical care). One paper [48] used a modified version of the AIS.

Six included papers (14\%) defined injurious falls only by fractures whereupon one study [40] defined hip fractures and non-hip fractures and five did not specify the type of fracture [41-45]. Seven articles (14\%) defined injurious falls only by healthcare use by either using unspecific terms such as "medical treatment" [70,71] or "medical care" [73] or specific definitions such as "hospital visits or admission for the treatment of a fracture or suspected fracture" [72].

A considerable number of articles $(\mathrm{n}=15,37 \%)$ used heterogeneous definitions by either defining symptoms ( $\mathrm{n}=7,17 \%$ ) or by combining symptoms and healthcare

\section{References included by} search terms $(n=2089)$
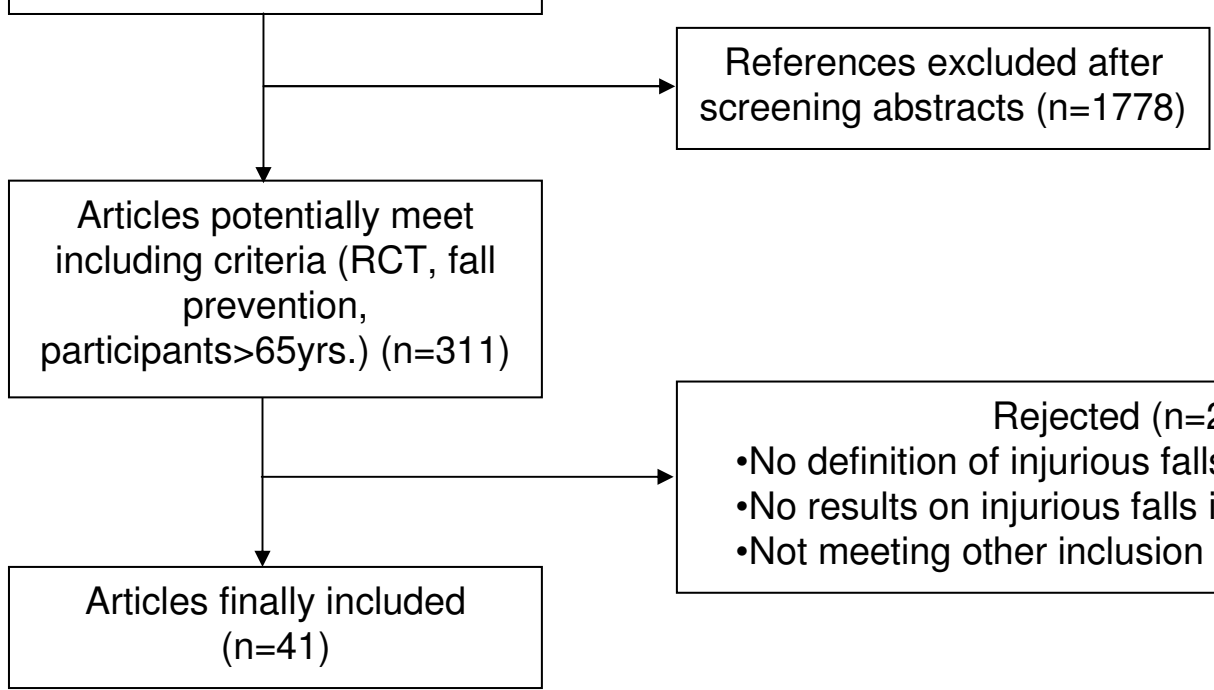

Rejected $(n=270)$

- No definition of injurious falls $(n=187)$

- No results on injurious falls in outcomes $(n=51)$

- Not meeting other inclusion criteria $(n=32)$

Figure 1 Flowchart of the process of literature search and extraction of RCTs meeting the inclusion criteria. 
Table 1 Types of definitions used to describe injurious falls in RCTs

\begin{tabular}{ll}
\hline Type of definition, $\mathbf{n}(\%)$ & Description of definition \\
\hline Based only on symptoms, 16 (39\%) & \\
\hline $\begin{array}{ll}\text { Fractures only, } \\
6(14 \%)\end{array}$ & - Hip fractures and non-hip fractures [40] \\
\hline AlS definition, & - All fractures [41-45] \\
$3(7 \%)$ & threatening injury, $5=$ critical injury [46,47] \\
& - Adapted AlS Scale ranging from "no injury, no pain" (level 1) to "fractures of hip, leg, or skull" (level 7) [48] \\
\hline Other definitions, & - Bruises, strains, cuts and abrasions, back pain and fractures [49,50] \\
$7(17 \%)$ & - Any detectable residual adverse physical change persisting beyond 1 hr after the fall [51] \\
& - Fractures or soft tissue injuries [52] \\
& - Cuts and bruises, fractures or other trauma [53] \\
& - If participants indicated that they were injured by the fall, irrespective of the severity of the injuries [54] \\
\hline
\end{tabular}

Based on symptoms and healthcare

use, 18 (44\%)

FICSIT definition, $\quad$ O Original FICSIT definition: Fractures, head injuries requiring hospitalisation, joint dislocations, sprains and $4(10 \%) \quad$ lacerations requiring suturing [56,57]

- Modified FICSIT definition: fractures, other head injuries with altered consciousness, joint dislocations or sprains, or sutured lacerations [58]; Fractures, head injuries requiring hospitalisation, joint dislocations, severe sprains and lacerations requiring suturing [59]

Definition according to Campbell et al. . Serious: fracture or admission to hospital or if any wounds needed stitches (sutures); moderate: bruising, [36], $6(15 \%)$ sprains, cuts, abrasions, or a reduction in physical function for at least three days, or if the participant sought medical help [36-39,60,61]

Other definitions, - dislocations, injuries of chest, abdomen, or pelvis; open wounds requiring suturing; injuries to blood $8(20 \%) \quad$ vessels; crushing injuries; and injuries to nerves and spinal cord [62]

- Injury: any sequelae relating from a fall; serious injury: sprains, joint dislocation, hip fracture, other fracture, transfer to acute hospital, urgent physician visit, radiological examination [63]

- Injury falls: any fracture, strain, sprain, laceration, or persistent pain (more than seven days); Medical care

falls: any fall for which medical care was sought; Fracture falls and hospitalised falls [64]

- Fractures, dislocations and soft tissue injuries needing suturing and even more severe injuries [65]

- Fractures, head injuries, sprains, bruises, scrapes, or other serious joint injuries, or if the participant sought medical care [66]

- Medical attention falls were coded ranging from no injury (0) to broken bone (4) [67]

- Cut, scrape, gash, bruise or fracture; a head injury resulted or where the fall resulted in hospitalisation [68] - Fractures and hospital admission [69]

$\begin{aligned} & \text { Based only on healthcare use, } \mathbf{7} \\
& (\mathbf{1 7 \% )}\end{aligned}$
\begin{tabular}{ll}
\hline Healthcare use definition, & - Medical treatment [70,71] \\
& - Hospital visits or admission for the treatment of a fracture or suspected fracture [72] \\
& - Medical care [73] \\
& - Falls requiring medical attention [74] \\
& - Doctor's or hospital attendance [75] \\
& - General practitioner or emergency department or admission to the hospital [76]
\end{tabular}

$\mathrm{n}=$ number of articles used a specific definition; AIS = Abbreviated Injury Scale [77]; FICSIT = Frailty and Injuries: Cooperative Studies of Intervention Techniques [78]

use $(\mathrm{n}=8,20 \%)$. These types of definitions ranged from single sentences including a variety of symptoms (e.g. bruises, strains, cuts and abrasions, back pain and fractures $[49,50])$ regardless of severity to multiple-level definitions categorising injurious falls according to five levels of severity (from no injury [level 0] to broken bone [level 4] [67]). The majority of studies $(\mathrm{n}=30$; 73\%; [36,38-45,49-55,58,61-64,67-70,72-76]) did not provide a reference for the definition of an injurious fall.

\section{Methods of collecting injurious falls data}

Table 2 details the methods of collecting injurious falls data used in RCTs. There was considerable heterogeneity in reporting systems and the time period over which information was collected. Three main methods of collecting falls data were found in the articles: (i) prospective reporting systems using calendars, postcards or diaries ( $\mathrm{n}=33,80 \%)$; (ii) retrospective reporting systems using telephone interview or postal questionnaire $(\mathrm{n}=30,73 \%)$; (iii) medical records $(\mathrm{n}=$ 18, 44\%). Prospective registration systems requested immediate return of the data, or return at specified time points ranging from one week to three months. Studies used prospective reporting systems often followed up with data collection by secondary data capture mechanisms where by telephone calls $(82 \%)$, hospital records 
Table 2 Methods of collecting injurious falls data

\begin{tabular}{|c|c|c|c|c|c|}
\hline \multirow[t]{2}{*}{ Ref. } & \multicolumn{3}{|c|}{ Prospective } & \multirow[t]{2}{*}{ Retrospective } & \multirow[t]{2}{*}{ Medical record } \\
\hline & Method & Recording & Reporting & & \\
\hline \multicolumn{6}{|c|}{ Fracture definition } \\
\hline [40] & Calendar & daily & not specified & - & Radiological \\
\hline [44] & Calendar & weekly & not specified & Postal Questionnaire & - \\
\hline [41] & Diary & after fall & every three weeks & - & Hospital, Other ${ }^{4}$ \\
\hline [45] & Calendar & daily & monthly & Phone $e^{1,2}$ & - \\
\hline$[42]$ & Diary & daily & Every two month & Phone ${ }^{3}$ & Radiological \\
\hline [43] & Calendar & daily & monthly & Phone $e^{1,2}$ & Radiological \\
\hline \multicolumn{6}{|c|}{ AIS definition } \\
\hline [46] & not specified & daily & after fall & - & Hospital \\
\hline [47] & - & - & - & - & Hospital \\
\hline [48] & Diary & daily & monthly & Phone $^{3}$ & - \\
\hline \multicolumn{6}{|c|}{ FICSIT definition } \\
\hline [56] & Calendar & daily & monthly & Phone $e^{1,2}$ & - \\
\hline [57] & Calendar & daily & monthly & Phone $^{3}$ & Hospital, Other ${ }^{4}$ \\
\hline [58] & - & - & - & - & $\begin{array}{c}\text { Hospital, Radiological, } \\
\text { Other }^{4}\end{array}$ \\
\hline [59] & Calendar & daily & monthly & Phone $e^{1,2}$ & - \\
\hline \multicolumn{6}{|c|}{ Campbell et al. Definition } \\
\hline [36] & Calendar & daily & monthly & Phone $e^{1,2}$ & Hospital \\
\hline$[60]$ & Calendar & daily & monthly & Phone $e^{1,2}$ & Hospital \\
\hline [38] & Calendar & daily & monthly & Phone ${ }^{2}$ & Other ${ }^{4}$ \\
\hline [37] & Calendar & daily & monthly & Phone $e^{1,2}$ & - \\
\hline [61] & Calendar & daily & monthly & Phone $^{2}$ & Hospital, Other ${ }^{4}$ \\
\hline [39] & Calendar & daily & monthly & Phone $e^{1,2}$ & - \\
\hline \multicolumn{6}{|c|}{ Health care use definition } \\
\hline [71] & - & - & - & - & Hospital, Other \\
\hline [70] & Diary & daily & monthly & Phone $e^{1,2}$ & - \\
\hline [72] & Calendar & weekly & monthly & Phone $e^{1,2}$ & - \\
\hline [73] & Calendar & daily & monthly & Phone $^{3}$ & - \\
\hline [74] & - & - & - & Phone $^{3}$ & - \\
\hline [75] & Diary & daily & $\begin{array}{c}\text { After } 3,6 \text { and twelve } \\
\text { month }\end{array}$ & Phone $^{3}$ & - \\
\hline [76] & Diary & daily & monthly & Phone $^{3}$ & Hospital \\
\hline \multicolumn{6}{|c|}{ Other definitions } \\
\hline$[50]$ & - & - & - & $\begin{array}{l}\text { Phone }{ }^{1} \text {, Postal } \\
\text { Questionnaire }\end{array}$ & - \\
\hline [49] & Calendar & daily & monthly & Phone $e^{1,2}$ & - \\
\hline [51] & Postcard & weekly & monthly & Phone ${ }^{1}$ & - \\
\hline [52] & - & - & - & - & $\begin{array}{c}\text { Hospital, Radiological, } \\
\text { Other }^{4}\end{array}$ \\
\hline [53] & Diary & daily & monthly & - & - \\
\hline [54] & Calendar & daily & monthly & Phone $e^{1,2}$ & - \\
\hline [55] & Calendar & daily & monthly & Phone ${ }^{3}$ & - \\
\hline [62] & Diary & daily & monthly & Phone $e^{2,3}$ & - \\
\hline [63] & Calendar & daily & monthly & - & Radiological \\
\hline [64] & $\begin{array}{l}\text { Calendar, } \\
\text { Postcard }\end{array}$ & daily & $\begin{array}{c}\text { every three month, } \\
\text { after fall }\end{array}$ & Phone $e^{2,3}$ & - \\
\hline [65] & - & - & - & Phone $^{3}$ & Hospital, Other ${ }^{4}$ \\
\hline [66] & Calendar & daily & every three month & - & Hospital, Other ${ }^{4}$ \\
\hline [67] & Diary & daily & every two weeks & Phone $^{1}$ & - \\
\hline [68] & Calendar & daily & monthly & - & - \\
\hline [69] & Postcard & - & monthly & Phone $^{1}$ & - \\
\hline
\end{tabular}


Table 2 Methods of collecting injurious falls data (Continued)

\begin{tabular}{|c|c|c|c|c|c|}
\hline $\begin{array}{l}\text { Method applied in } \mathrm{n}\left(\%^{5}\right) \text { of } \\
\text { studies: }\end{array}$ & $\begin{array}{c}\text { Calendar: } \\
\text { n = } 22(54 \%) \\
\text { Postcard: } \\
\text { n = } 3(7 \%) \\
\text { Diary: } \\
\text { n }=9(22 \%) \\
\text { not specified: } \\
\text { n }=1(2 \%) \\
\text { not applied (-): } \\
\text { n }=7(17 \%)\end{array}$ & $\begin{array}{c}\text { daily: } \\
n=29(71 \%) \\
\text { weekly: } \\
n=3(7 \%) \\
\text { after fall: } \\
n=1(2 \%) \\
\text { not applied (-): } n=8 \\
(20 \%)\end{array}$ & $\begin{array}{c}\text { weekly: } \\
n=2(5 \%) \\
\text { monthly: } \\
n=29(71 \%) \\
\text { after fall: } \\
n=2(5 \%) \\
\text { not specified: } \\
n=2(5 \%) \\
\text { not applied (-): } n=7 \\
(17 \%)\end{array}$ & $\begin{array}{c}\text { Phone: } n=29(71 \%) \\
\text { Postal Questionnaire: } \mathrm{n}= \\
2(5 \%) \\
\text { not applied(-): } \mathrm{n}=11 \\
(27 \%)\end{array}$ & $\begin{array}{c}\text { Radiological: } \\
\text { n =6 (15\%) } \\
\text { Hospital: } \\
\text { n = } 13(32 \%) \\
\text { Other: } \\
\text { n =9 (22\%) } \\
\text { not applied (-): } \\
\text { n = 23(56\%) }\end{array}$ \\
\hline
\end{tabular}

Given are the methods of collecting injurious falls data in the articles included in the review. $\mathrm{n}=$ number of studies; AIS = Abbreviated Injury Scale; FICSIT = Frailty and Injuries: Cooperative Studies of Intervention Techniques

${ }^{1}$ if calendar, diary, or postcard not returned; ${ }^{2}$ following occurrence of a fall; ${ }^{3}$ regular phone call; ${ }^{4}$ records from nursing homes, physicians or emergency departments; ${ }^{5}$ calculation of percentages: number of articles used a specific method/total number of articles * 100 , percentages may sum up to more than 100 percent as some studies used multiple methods

(24\%), records from nursing homes, physicians or emergency departments $(15 \%)$ or radiological records $(12 \%)$ were used.

Studies using the Campbell et al. definition [36-39,60,61] consistently collected data by prospective daily recording with calendars, monthly reporting, and telephone interview follow up. In contrast there was little consistency in methods of data collection among studies that used other types of definitions (FICSIT, fracture, AIS, health care use, other).

Three studies $(7 \%)[47,52,58]$ collected data on injurious falls only by the use of medical records whereupon information was gathered from hospitals [47,52,58], nursing homes $[47,52,58]$, radiology departments [52,58], emergency departments [52,58], or physicians' records $[52,58]$.

\section{Proportion of injurious falls to all falls}

For 27 (65.9\%) studies the proportion of injurious falls to all falls was computed (Table 3). For 13 (31.7\%) studies $[44,45,50-53,57,58,65,69,71-73]$ calculation of the proportion of injurious falls is not possible as data on the number of falls and/or number of injurious falls are not available. Two papers $[36,39]$ use the same data, one paper [39] is therefore not included in Table 3.

Calculation of the proportion of falls which are injurious allows a comparison of injurious falls outcomes across studies. A considerable range (3.6\%-63.5\%) in the proportion of injurious falls is apparent. The proportion appears to be related to the type of definition used: lowest proportions are found in studies that defined injurious falls as fractures only $(0.4 \%-11.3 \%)$, studies using multi-level definitions such as the AIS report higher proportions $(23.4 \%-56.2 \%)$ and the highest proportion $(63.5 \%)$ is found if a single definition had been used which included a range of symptoms (e.g. back pain, bruises, strains, cuts and abrasions, and fractures [49]).

For the proportion of total injurious falls reported across studies, variation is high $(\mathrm{CV}=50.1 \%)$.
Considerable variation between studies is also apparent for subcategories of injurious falls in terms of fractures $(\mathrm{CV}=51.5 \%)$, serious $(\mathrm{CV}=68.0 \%)$ and moderate $(\mathrm{CV}$ $=35.4 \%$ ) falls. However, variation is related to the standardisation of definition and outcomes: for the group of studies using versions of the Campbell et al definition, variation in the proportion of all injurious falls is considerably lower $(\mathrm{CV}=12.0 \%)$ compared to variation of other studies included in the analysis $(\mathrm{CV}=66.3 \%)$. The same result is obtained for the subcategories: across studies which applied the Campbell et al. definition a lower variation is apparent for proportion of serious (CV: Campbell et al.: $38.3 \%$ vs. other studies: $75.2 \%)$ and moderate (CV: Campbell et al.: $20.1 \%$ vs. other studies: $35.5 \%$ ) injurious falls compared to all studies included.

In those studies using healthcare definitions $(\mathrm{n}=10$, $24.4 \%$ ) the proportion of injurious falls varies substantially (2.9-30.4\%) leading to a high CV of $46.8 \%$. Lowest proportion is apparent for injurious falls defined as "hospitalisation" (2.9\% [64]), whereas high proportions of injurious falls are apparent if unspecific "medical care" definitions are used (14.6-23.6\% [38,59,61,64]) (Table 3).

\section{Methods of summarising injurious fall outcomes}

Table 4 details the methods used to summarise data on injurious falls in identified articles. The way data are summarised differs across papers. The most frequently reported summary statistic is the number of participants sustaining an injurious fall ( $\mathrm{n}=17,41 \%)$ and the number of injurious falls ( $n=17,41 \%)$.

Some papers report on injurious falls by specifying the number of participants sustaining medical care falls ( $\mathrm{n}=$ $5,12 \%)$ and/or the number of medical care falls $(\mathrm{n}=11$, $27 \%)$. A few articles $(n=3,7 \%)$ report on the number of falls requiring hospital admission. Fracture falls are specified in some papers as number of events $(n=11$, $27 \%)$ and in some as number of participants $(n=11$, $27 \%$ ). Categories of injurious falls partly overlap as some 
Table 3 Falls and proportion of injurious falls as reported in the RCTs

\begin{tabular}{|c|c|c|c|c|c|c|c|}
\hline \multirow[t]{2}{*}{ Ref. } & \multirow[t]{2}{*}{ Sample size, $\mathrm{n}$} & \multirow[t]{2}{*}{ All falls, $n$} & \multicolumn{5}{|c|}{ Proportion of injurious falls to all falls, $\%$ (n) } \\
\hline & & & Total & Fracture & Serious & Moderate & Healthcare use \\
\hline \multicolumn{8}{|c|}{ Definitions based only on symptoms } \\
\hline \multicolumn{8}{|c|}{ Fracture definition } \\
\hline [40] & 981 & 1527 & $4.5 \%(68)$ & $\begin{array}{l}2.1 \%(32)^{1} \\
2.4 \%(36)^{2}\end{array}$ & - & - & - \\
\hline [41] & 196 & 460 & $3.6 \%(7)$ & $3.6 \%(7)^{3}$ & - & - & - \\
\hline [42] & 242 & 275 & $11.3 \%(31)$ & $11.3 \%(31)^{3}$ & - & - & - \\
\hline [43] & 2.256 & 5.404 & $4.6 \%(246)$ & $4.6 \%(246)^{3}$ & - & {$[59.2 \%(3.198)]^{8}$} & - \\
\hline \multicolumn{8}{|c|}{ AIS definition } \\
\hline [46] & 384 & 619 & $23.4 \%(145)$ & $\begin{array}{l}2.4 \%(15)^{4} \\
2.9 \%(18)^{5}\end{array}$ & - & $18.1 \%(112)^{9}$ & - \\
\hline [47] & 199 & 78 & $28.2 \%(22)$ & $\begin{array}{l}2.6 \%(2)^{1} \\
2.6 \%(2)^{2}\end{array}$ & - & $23.1 \%(18)^{7}$ & - \\
\hline [48] & 230 & 89 & $56.2 \%(50)$ & $\begin{array}{l}1.1 \%(1)^{1} \\
4.5 \%(4)^{2}\end{array}$ & $14.6 \%(13)^{6}$ & $36 \%(32)^{10}$ & - \\
\hline \multicolumn{8}{|c|}{ Other definition } \\
\hline [49] & 597 & 510 & $63.5 \%(324)$ & - & - & - & - \\
\hline [54] & 186 & 322 & $39,4 \%(127)$ & - & - & - & - \\
\hline [55] & 597 & 957 & $48,0 \%(459)$ & - & - & - & - \\
\hline [62] & 360 & 367 & $8.2 \%(30)$ & $1.9 \%(7)^{3}$ & $6.3 \%(23)$ & - & - \\
\hline \multicolumn{8}{|c|}{ Definitions based on symptoms and health care use } \\
\hline \multicolumn{8}{|c|}{ FICSIT definition } \\
\hline [56] & 288 & 238 & $24.0 \%(57)$ & - & $24.0 \%(57)$ & - & - \\
\hline \multirow[t]{2}{*}{ [59] } & 291 & 258 & $35.7 \%(92)$ & - & $12.0 \%(31)$ & - & $23.6 \%(61)^{11}$ \\
\hline & \multicolumn{7}{|c|}{ Campbell et al. definition } \\
\hline [36] & 233 & 240 & $45.8 \%(110)$ & - & $10.4 \%(25)$ & $35.4 \%(85)$ & - \\
\hline [60] & 152 & 358 & $40.5 \%(145)$ & - & $9.5 \%(34)$ & $31.0 \%(111)$ & - \\
\hline [38] & 391 & 443 & $51.5 \%(228)$ & - & $6.8 \%(30)$ & $44.7 \%(198)$ & $25.5 \%(113)^{11}$ \\
\hline [37] & 312 & 584 & $55.8 \%(326)$ & - & $3.6 \%(21)$ & $52.2 \%(305)$ & - \\
\hline \multirow[t]{2}{*}{ [61] } & 240 & 189 & $48.1 \%(91)$ & - & $5.8 \%(11)$ & $42.3 \%(80)$ & $23.3 \%(44)^{11}$ \\
\hline & \multicolumn{7}{|c|}{ Other definition } \\
\hline [63] & 547 & 1299 & $40.3 \%(523)$ & - & $4.2 \%(54)$ & - & - \\
\hline [64] & 3.182 & 3.814 & $30.5 \%(1.163)$ & $5.1 \%(193)^{3}$ & - & - & $\begin{array}{c}14.6 \%(558)^{11} \\
2.9 \%(111)^{12}\end{array}$ \\
\hline [66] & 188 & 111 & $21.6 \%(24)$ & - & $2.7 \%(3)$ & $18.9 \%(21)$ & $17.1 \%(19)^{12}$ \\
\hline [67] & 70 & 546 & $14.6 \%(80)$ & $\begin{array}{c}0.4 \%(2)^{1} \\
3.3 \%(18)^{2}\end{array}$ & - & - & - \\
\hline \multirow[t]{2}{*}{ [68] } & 1.090 & 1.448 & $55.5 \%(804)$ & - & - & - & $8.6 \%(124)^{13}$ \\
\hline & \multicolumn{7}{|c|}{ Definitions based only on health care use } \\
\hline [70] & 27 & 23 & $30.4 \%(7)$ & - & - & - & $30.4 \%(7)^{14}$ \\
\hline [74] & 3.139 & 3.776 & $21.7 \%(821)$ & - & - & & $21.7 \%(821)^{15}$ \\
\hline [75] & 349 & 224 & $13.5 \%(47)$ & - & - & - & $\begin{array}{l}9.2 \%(32)^{16} \\
4.3 \%(15)^{17}\end{array}$ \\
\hline \multirow[t]{3}{*}{ [76] } & 392 & 820 & $12.2 \%(100)$ & - & - & - & $12.2 \%(100)^{12,16,17}$ \\
\hline & Range: & & $3.6-63.5 \%$ & $0.4-11.3 \%$ & $2.7-24.0 \%$ & $18.1-52.2 \%$ & $2.9-30.4 \%$ \\
\hline & CV: & & $50.1 \%$ & $51.5^{18}$ & $68.0 \%$ & $35.4 \%$ & $46.8 \%$ \\
\hline
\end{tabular}

Displayed are falls (number) and injurious falls (proportion = injurious falls/falls $* 100$; number) as reported in the RCTs. Injurious falls data are given for the following categories: total, fracture, serious, moderate, healthcare use

$\mathrm{n}=$ number; AIS = Abbreviated Injury Scale; FICSIT = Frailty and Injuries: Cooperative Studies of Intervention Techniques. CV = Coefficient of variation [(SD/mean) $\times 100])$ as a measure of the variability (\%) of injurious falls outcomes between studies. ${ }^{1}$ Hip fracture; ${ }^{2}$ other fracture (except hip); ${ }^{3}$ fracture type not specified; ${ }^{4}$ hip or other femoral fractures; ${ }^{5}$ vertebral or wrist fracture; ${ }^{6}$ pain, injury, medical help required; ${ }^{7}$ Injuries; no fracture; ${ }^{8}$ bruise, abrasion or muscle injury without fracture, results are not included in analysis as only fractures were defined; ${ }^{9}$ superficial wounds and bruises; ${ }^{10}$ pain, minor injury, friends help needed, Bruises and no help needed; ${ }^{11}$ medical care; ${ }^{12}$ hospitalised falls; ${ }^{13}$ medical treatment; ${ }^{14}$ hospitalisation, emergency department visits or physician visits; ${ }^{15}$ medical attention; ${ }^{16}$ general practitioner surgery; ${ }^{17}$ accident and emergency department; ${ }^{18}$ total fracture incidence per study For the following reference calculation of the proportion of injurious falls is not possible as data on the number of falls and/or number of injurious falls are not available: $[44,45,50-53,57,58,65,69,71-73]$. Reference [39] uses the same data as [36] and is therefore not included in the table 
Table 4 Methods of summarising injurious fall outcomes

\begin{tabular}{lcl}
\hline Data reported & Articles $\mathbf{n}(\%)$ & Reference \\
\hline Number of participants sustaining injurious falls & $17(41 \%)$ & {$[36,38,40,41,47,51,53,55,59,63,65-67,70,72,73,76]$} \\
Sustaining medical care falls & $5(12 \%)$ & {$[53,59,69,74,75]$} \\
Sustaining fracture falls & $11(27 \%)$ & {$[40-44,46,47,53,55,69,75]$} \\
Number of injurious falls & $17(41 \%)$ & {$[43,46,48,49,52,54,55,58,59,61,63,64,67,68,71,73,76]$} \\
Medical care falls & $11(27 \%)$ & {$[38,39,56,59,61,64,66,68,74-76]$} \\
Fracture falls & $11(27 \%)$ & {$[40,42,43,45,52,58,62,64,67,71,76]$} \\
Falls requiring hospital admission & $3(7 \%)$ & {$[58,59,64]$} \\
Injury rate & $4(10 \%)$ & {$[40,52,54,65]$} \\
Injurious fall rates & $8(20 \%)$ & {$[37-39,56,58,61-63]$} \\
Mean number of injurious falls per participants & $5(12 \%)$ & {$[37,40,49,63,67]$} \\
Injurious falls/person time & $11(27 \%)$ & {$[40]^{1},[54]^{1},[62]^{5},[38]^{4},[61]^{2},[63]^{4},[68]^{4},[58]^{4},[52]^{4},[2]^{2},[39]^{4}$} \\
Serious injury/person time & $3(7 \%)$ & {$[37,38,63]^{2}$} \\
Moderate injury/person time & $2(5 \%)$ & {$[37,38]^{2}$} \\
Medical care falls/person time & $1(2 \%)$ & {$[56,68]^{4}$} \\
Soft tissue/person time & $1(2 \%)$ & {$[52]^{1}$} \\
Hip fracture/person time & $2(5 \%)$ & {$[40,52]^{1}$} \\
Other fracture/person time & $2(5 \%)$ & {$[40,52]^{1}$} \\
Time to injurious fall event & $4(10 \%)$ & {$[43,48,57,76]$} \\
\hline
\end{tabular}

Methods of fall documentation used in the articles. $n=$ number of studies; calculation of percentages: number of articles used a specific method/total number of articles * 100; ${ }^{1}$ number/1000 persons year; ${ }^{2}$ number/persons year; ${ }^{3}$ number/10 persons year; ${ }^{4}$ number/100 persons year

studies report on both less specific types of injurious falls (e.g. medical care falls) and more specific types of injurious falls (e.g. fracture falls) whereas other studies only report one category.

Beside absolute values, several articles report rates of injurious falls or fall-related injuries. Calculation of rates was inconsistent. Some studies calculated the mean number of injurious falls per participant $(n=5,12 \%)$. A number of studies calculated a particular relationship between a numerator and a denominator, where the denominator included time measurement. Different types of numerators (severity of injury, type of injury such as fracture or soft tissue) and denominators (resident year, 10 resident years, 100 person years, 1000 person years) had been used for calculation (Table 4).

\section{Discussion}

The results of this review highlight that existing fall prevention RCTs substantially vary in their methods of defining, collecting, and reporting injurious falls. No method has to date been implemented as a designated standard. Instead, a variety of approaches to defining and categorising injurious falls are identified. The use of different approaches leads to substantial differences in study results and thus limits the comparability of findings, and makes interpretation difficult.

\section{Injurious fall definition}

A large variety of definitions, in a number of cases not referenced, are identified in the present review. Some studies defined only specific injuries, such as fractures, while others collapsed multiple symptoms related to injurious falls into a single definition. The proportion of injurious falls to all falls reported substantially increases if several symptoms of different grades of severity are included into a single definition. For example, Lord [49] defined bruises, strains, cuts and abrasions, back pain and fractures and reported $63.5 \%$ of all falls were injurious. In contrast, Becker included only radiologically confirmed fractures resulting in $4.5 \%$ being reported as injurious falls. Although some of the differences between studies might be explained by the different populations and settings, the high proportion of injurious falls in the Lord study is most likely due to the inclusion of falls that caused minor injuries [49].

Inconsistent definitions with respect to healthcare use limit the comparability of RCTs, e.g. studies which used the FICSIT definition $[56,59]$ included injurious falls predominantly requiring medical care and thus reported lower proportions of injurious falls (24-35.7\%) compared to a study [49] which uses definitions based on multiple symptoms $(63.5 \%)$ not all necessitating medical care use (e.g. abrasion, back pain).

Various definition of healthcare use can be identified ranging from specific interventions such as "suturing" to unspecific terms such as "medical treatment" or "urgent physician visits"and this exacerbates problems in comparing comparability of study outcomes. Methodological problems in injury research with respect to healthcare use have been discussed elsewhere [32]. If medical care 
services are used as a measure of injury, then the definition of injury becomes entangled with service configuration and policy issues, the type and availability of care and factors that influence care-seeking behaviour, including personality, pain tolerance, and anxiety [32].

Grouping injuries by severity, as found in several studies included in this review, is important; however, the use of different schemes can lead to confusion and makes it difficult to compare findings [32]. Authors who used differentiated scales for severity classification such as the AIS (seven categories) [48] summarised single categories into one (e.g. 4-7) either in order to facilitate statistical analysis or to compare results with other studies that used only one or two categories. However, the way severity categories were collapsed differ between studies and hamper the comparability of outcomes. A small change in the definition of injury severity can substantially influence the reported proportion of injurious falls as indicated by the following example: use of the expression "severe sprains" in the FICSIT definition resulted in $12 \%$ of falls being serious injurious falls [59]. In contrast $24 \%$ of falls were serious injurious falls were reported if "sprains" (without the word "severe") were defined [56].

Overall, the adverse impact of the variability in definitions and categorisation systems is reflected by the substantial variation of the proportion of injurious falls across studies. High CVs were found for the proportion of all injurious falls as well as for subgroups or fracture, serious, moderate and healthcare falls. However, one of the major findings of the present review is that a strict standardisation of the definition could substantially enhance comparability of studies. This is reflected by the group of RCTs which defined injurious falls according to Campbell et al. [36-39,60,61]. Whereas high variation had been obtained between outcomes of all RCTs included in this review, variation was considerably lower across those studies which applied the standardised Campbell et al. definition. This highlights the importance of using a standardised definition in future.

\section{Methods of collecting injurious falls data}

The high variation in proportion of injurious falls found in the present study may not only be due to the varying definitions, but also to different assessment methods. Several studies did not record injurious falls prospectively $[47,50,52,58,65,71,74]$ or did not follow up prospective data collection to verify information on injurious falls, e. g. by phone call $[40,41,46,47,53,63,66,68]$. In addition, periods of recording data by the study centre substantially varied (from three weeks to three months) between studies. Long delay between event and data recording might limit the verification of injurious falls information. Thus, in particular due to short recovery periods of soft- tissue injuries [13] and memory deficits in the elderly [79] prospective daily recording in combination with short latency periods for reporting information to the study centre is essential to gather valid information about injurious falls [13].

Interestingly, we found that those RCTs which had higher consistency in the proportion of injurious falls (RCTs using the Campbell et al. definition) used similar methods for data collection suggesting that a standardised assessment enhances the comparability of results.

Some variation in proportion of injurious falls might be related to the limited standardisation of medical records. Medical reports have been recommended for confirming prospective injurious falls data and verifying severity of injury [78]. Radiological confirmation of fractures has been requested as a gold standard [13]. However, only $44 \%$ of the authors used medical reports as a data source and radiological confirmation of fractures was reported in only $15 \%$ of the RCTs included in the review. Accuracy of self-report of fracture is questionable since its agreement with radiologic diagnosis is limited [80].

Studies differed considerably with respect to the type of patient reports used. Some studies included nursing home reports $[41,52,58]$ whereas others only included reports of physicians $[38,46,57,60,63]$ or emergency departments $[46,57,63]$. As records can differ in validity [13] this might explain some of the variability, particularly in those studies $[47,52,58]$ which used medical reports as a primary data source.

\section{Injurious falls documentation}

The way data are summarised differs among articles. Several studies reported on the number of injurious falls or on injurious fallers, whereas others specified fractures or reported on medical care falls. Selection of outcomes depends on the predefinition of specific endpoints such as serious injuries or fractures. For a number of studies the calculation of the proportion of injurious falls was not possible as data on the number of falls and/or injurious falls were not given and only fallers, injurious fall rates or fall rate ratios were reported. Varying numerators (fracture, serious, moderate, healthcare use) and different time denominators (1-1000 years) additionally exacerbate the comparability of outcomes as recently highlighted standardised documentation of injuries is a crucial issue for injury epidemiology and should be implemented in future studies [81].

\section{Development of a standardised methodology for future RCTs}

To date no standardised methodology exists for defining, assessing, and reporting injurious falls in RCTs, and thus needs to be developed for future research. 
The most robust measure of injurious falls is considered to be peripheral fracture rate, verified by radiological evidence $[13,29,78]$. However, definition of fractures as primary endpoint requires large sample sizes $[29,82]$. By way of example, we determined sample sizes in order to detect statistically significant differences in outcomes related to falls and injurious falls (Table 5). The calculations demonstrate that, for instance, in a study population with a hip fracture incidence of $3 \%$ (medium risk) [83] a sample close to 42.000 study participants would be needed to observe a significant effect of an intervention if it reduced the hip fracture incidence by 15\% (significance level 5\%, power $80 \%$ ). Based on this assumption no study in the present review met the requisite sample size calculation disallowing any statement on effectiveness of interventions with respect to falls resulting in hip fracture.

Including a range of fall-related injuries into one definition substantially increases the incidence of injurious falls and thus requires smaller sample sizes to achieve adequate statistical power. However, if several symptoms are included then a proper definition with respect to severity and the use of medical care is essential for comparability of results. Established scales such as the AIS

\begin{tabular}{|c|c|c|}
\hline Outcome & $\begin{array}{l}\text { Incidence in study } \\
\text { population }\end{array}$ & $\begin{array}{c}\text { Required sample } \\
\text { size }\end{array}$ \\
\hline \multicolumn{3}{|c|}{ Low risk ( $25 \%$ lower than intermediate risk) } \\
\hline Fallers ${ }^{1}$ & $37.50 \%$ & 2246 \\
\hline $\begin{array}{l}\geq 1 \text { injurious } \\
\text { falls }\end{array}$ & $15.00 \%$ & 7408 \\
\hline$\geq 1$ fractures & $3.75 \%$ & 33222 \\
\hline $\begin{array}{l}\geq 1 \text { hip } \\
\text { fractures }\end{array}$ & $2.25 \%$ & 56168 \\
\hline \multicolumn{3}{|c|}{ Intermediate risk } \\
\hline Fallers $^{1}$ & $50.00 \%$ & 1386 \\
\hline$\geq 1$ injurious & $20.00 \%$ & 5258 \\
\hline$\geq 1$ fractures & $5.00 \%$ & 24618 \\
\hline $\begin{array}{l}\geq 1 \text { hip } \\
\text { fractures }\end{array}$ & $3.00 \%$ & 41828 \\
\hline \multicolumn{3}{|c|}{ High risk ( $25 \%$ higher than intermediate risk) } \\
\hline Fallers $^{1}$ & $62.50 \%$ & 868 \\
\hline $\begin{array}{l}\geq 1 \text { injurious } \\
\text { falls }\end{array}$ & $25.00 \%$ & 3966 \\
\hline$\geq 1$ fractures & $6.25 \%$ & 19456 \\
\hline $\begin{array}{l}\geq 1 \text { hip } \\
\text { fractures }\end{array}$ & $3.75 \%$ & 33222 \\
\hline
\end{tabular}

Assumptions for sample size calculation: effect size $-15 \%$ with respect to all outcomes, statistical power $80 \%$, significance-level $5 \%$, two-sided tests, not adjusted for multiple testing.

${ }^{1}$ Fallers reflect those study participants who experience any fall (injurious or not injurious) during the study period provide a differentiated severity scoring (7 categories); however, its utility for population-based research is limited due to the time-consuming assignment of scores [84]. In contrast, categorising serious and moderate injurious falls according to the definition of Campbell et al. is feasible, even in large scale studies. It is the most frequent type of definition that has been used consistently in different articles $(n=6,15 \%)$ included in the review. A meta-analysis, including RCTs and controlled trials, has been successfully conducted on the basis of the Campbell et al. definition [24].

According to our findings, a comprehensive, standardized system for categorising and defining serious, moderate and minor fall-related injuries by both symptoms and medical care use is recommendable for future RCTs of fall prevention (Table 6, Figure 2). Categories can be chosen for defining specific types on injurious falls depending on the research question and sample size calculation requirements. Each of the categories can be used independently as it is characterised by a standardised definition. Ideally, the injuries in each category should be reported even if a specific study is not powered to detect effects. Reporting all injuries will prevent an outcome bias and the data will be available for future meta-analysis. Data of medical care can be used for focus on cost calculation. A fall-related injury should be classified by an independent person, blind to group allocation.

Accuracy of moderate and minor injurious falls data is lower as the definition of injury becomes entangled with the type and availability of care and factors that influence care-seeking behaviour, including personality, pain tolerance, and anxiety [32] (Figure 2). However, research on falls causing minor injuries has been highlighted as an important issue as they have also serious consequences such as depression, fear of falling and activity restriction [14].

Injurious falls data should be collected by prospective daily recording, a minimum of monthly reporting, and telephone or face-to-face interview as recommended in a consensus paper on fall prevention studies [13]. We recommend standardised documentation of injurious falls data as number of injurious falls, number of people sustaining injurious falls, injurious falls rate per personyear of follow-up, and number of people sustaining multiple events [13]. Along with a standardised statistical analysis indicating the absolute risk difference between groups a common data set will improve comparability of future RCTs.

\section{Limitations}

Only RCTs in fall prevention were included in the present review and therefore it reflects the methodological status in this specific research area. We are aware that by this 
Table 6 Standardized system for categorizing and defining fall-related injuries

\begin{tabular}{ll}
\hline Category & Definition \\
\hline $\begin{array}{l}\text { a - serious injury } \\
\text { b- moderate }\end{array}$ & medically recorded fracture, head or internal injury requiring accident and emergency or inpatient treatment \\
injury & $\begin{array}{ll}\text { minor bruises or abrasions not requiring health professional assistance; reduction in physical function (e.g. due to pain, fear of } \\
\text { c- minor injury }\end{array}$ \\
$\begin{array}{l}\text { falling) for at least three days. } \\
\text { no physical injury detected }\end{array}$
\end{tabular}

pre-selection relevant data, including epidemiological sources may not have been considered. We also note that our inclusion only of papers that defined their terms may have resulted in exclusion of papers where the outcome might be considered self-evident, for example we may have underreported the number of papers reporting fracture if fracture was not defined as an injury.

\section{Conclusion}

To date, no method has been defined as an international standard for RCTs in the field of fall prevention. Defining serious and moderate injurious falls according to
Campbell et al. is the most frequently used methodology in RCTs to date and allow a comparison of study results. On the basis of this methodology we developed a standardised system for defining different categories of injuries which is feasible also in large scale studies. We recommend use of this system in future studies to reach a consensus on injurious falls methodology.

What is already known on this subject

- The combination of single randomised controlled trials in meta-analyses may help to generate evidence based data on specific prevention strategies to reduce injurious falls.

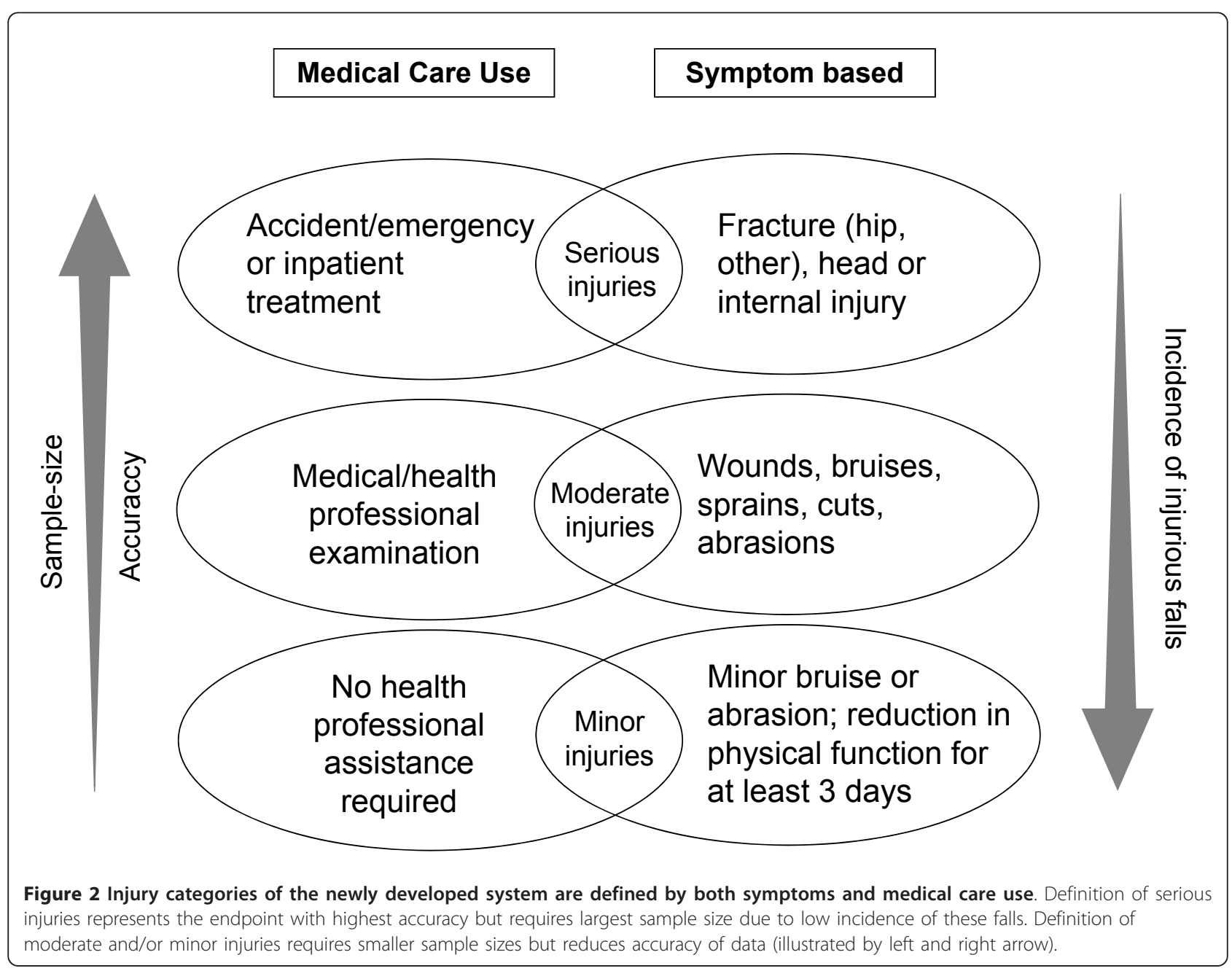


- The standardisation of the assessment methodology and case definition represents a major precondition for the conduction of meta-analyses.

- International guidelines provide recommendations for the standardisation of falls methodology; however, injurious falls have not been targeted.

\section{What this study adds}

- The definitions and methods used to measure and document injurious falls substantially vary in existing randomised controlled trials on fall prevention and thus hampering the comparability of study results and the conduction of meta-analyses.

- Our results highlight that the use of a standardised definition of injurious falls leads to a higher concurrence in study outcomes.

- Based on our results we recommend use of a standardised methodology in future randomised controlled trials including a comprehensive system for categorising and defining injurious falls and standardised methods of collecting and reporting on injurious falls data.

Funding

This study was supported by the Dietmar Hopp Stiftung, the Klaus Tschira Stiftung, the Robert Bosch Stiftung and the Landesgraduiertenförderung Baden-Württemberg.

\section{Author details}

'Department of Geriatric Research, AGAPLESION Bethanien-Hospital/Geriatric Center at the University of Heidelberg, Rohrbacherstr.149, Heidelberg 69126, Germany. ${ }^{2}$ Network Aging Research, University of Heidelberg, Heidelberg, Germany. ${ }^{3}$ Division of Clinical Epidemiology and Aging Research, German Cancer Research Center Heidelberg, Heidelberg, Germany. ${ }^{4}$ School of Nursing, Midwifery and Social Work and Manchester Academic Health Sciences Centre, University of Manchester, Manchester, UK.

\section{Authors' contributions}

MS: development of study concept and design, preparation of manuscript, interpretation of data, statistical analysis; AL: literature search, study selection, interpretation of data, preparation of manuscript, development of study design; CS: literature search, study selection, critical revision of manuscript; RRM: literature search; GM: literature search, study selection, critical revision of manuscript; CT: critical revision of manuscript; $\mathrm{KH}$ : study selection, development of study concept and design, critical revision of manuscript. All authors including PO contributed to the interpretation of data, drafting the article and final approval of published version. All authors read and approved the final manuscript.

\section{Competing interests}

The authors declare that they have no competing interests.

Received: 22 September 2011 Accepted: 17 April 2012

Published: 17 April 2012

\section{References}

1. Hausdorff JM, Rios DA, Edelberg HK: Gait variability and fall risk in community-living older adults: a 1-year prospective study. Arch Phys Med Rehabil 2001, 82(8):1050-1056.

2. Tinetti ME, Speechley M, Ginter SF: Risk factors for falls among elderly persons living in the community. N Engl J Med 1988, 319(26):1701-1707.

3. Tinetti ME, Williams CS: The effect of falls and fall injuries on functioning in community-dwelling older persons. J Gerontol A Biol Sci Med Sci 1998, 53(2):M112-M119.
4. Oakley A, Dawson MF, Holland J, Arnold S, Cryer C, Doyle Y, Rice J, Hodgson CR, Sowden A, Sheldon T, et al: Preventing falls and subsequent injury in older people. Qual Health Care 1996, 5(4):243-249.

5. van Weel C, Vermeulen $H$, van den Bosch W: Falls, a community care perspective. Lancet 1995, 345(8964):1549-1551.

6. Alexander BH, Rivara FP, Wolf ME: The cost and frequency of hospitalization for fall-related injuries in older adults. Am J Public Health 1992, 82(7):1020-1023.

7. Gillespie LD, Robertson MC, Gillespie WJ, Lamb SE, Gates S, Cumming RG, Rowe $\mathrm{BH}$ : Interventions for preventing falls in older people living in the community. Cochrane Database Syst Rev 2009, 2:CD007146.

8. Kannus P, Sievanen H, Palvanen M, Jarvinen T, Parkkari J: Prevention of falls and consequent injuries in elderly people. Lancet 2005, 366(9500):1885-1893.

9. Rubenstein LZ: Falls in older people: epidemiology, risk factors and strategies for prevention. Age Ageing 2006, 35(Suppl 2):ii37-ii41.

10. Sattin RW, Lambert Huber DA, DeVito CA, Rodriguez JG, Ros A, Bacchelli S, Stevens JA, Waxweiler RJ: The incidence of fall injury events among the elderly in a defined population. Am J Epidemiol 1990, 131(6):1028-1037.

11. Tinetti ME, Doucette J, Claus E, Marottoli R: Risk factors for serious injury during falls by older persons in the community. J Am Geriatr Soc 1995, 43(11):1214-1221.

12. Davis JC, Robertson MC, Ashe MC, Liu-Ambrose T, Khan KM, Marra CA: International comparison of cost of falls in older adults living in the community: a systematic review. Osteoporos Int 2010, 21(8):1295-1306.

13. Lamb SE, Jorstad-Stein EC, Hauer K, Becker C: Development of a common outcome data set for fall injury prevention trials: the Prevention of Falls Network Europe consensus. J Am Geriatr Soc 2005, 53(9):1618-1622.

14. Todd C, Skelton D: What are the main risk factors for falls among older people and what are the most effective interventions to prevent these falls? Copenhagen: WHO Regional Office for Europe (Health Evidence Network report); 2004.

15. Chang JT, Morton SC, Rubenstein LZ, Mojica WA, Maglione M, Suttorp MJ, Roth EA, Shekelle PG: Interventions for the prevention of falls in older adults: systematic review and meta-analysis of randomised clinical trials. BMJ 2004, 328(7441):680.

16. Costello $E$, Edelstein JE: Update on falls prevention for communitydwelling older adults: review of single and multifactorial intervention programs. J Rehabil Res Dev 2008, 45(8):1135-1152.

17. Cusimano MD, Kwok J, Spadafora K: Effectiveness of multifaceted fallprevention programs for the elderly in residential care. Inj Prev 2008, 14(2):113-122.

18. Sherrington C, Whitney JC, Lord SR, Herbert RD, Cumming RG, Close JC: Effective exercise for the prevention of falls: a systematic review and meta-analysis. J Am Geriatr Soc 2008, 56(12):2234-2243.

19. Gardner MM, Robertson MC, Campbell AJ: Exercise in preventing falls and fall related injuries in older people: a review of randomised controlled trials. Br J Sports Med 2000, 34(1):7-17.

20. Lin MR, Hwang HF, Wang YW, Chang SH, Wolf SL: Community-based tai chi and its effect on injurious falls, balance, gait, and fear of falling in older people. Phys Ther 2006, 86(9):1189-1201.

21. McClure R, Turner C, Peel N, Spinks A, Eakin E, Hughes K: Population-based interventions for the prevention of fall-related injuries in older people. Cochrane Database Syst Rev 2005, 1:CD004441.

22. Province MA, Hadley EC, Hornbrook MC, Lipsitz LA, Miller JP, Mulrow CD, Ory MG, Sattin RW, Tinetti ME, Wolf SL: The effects of exercise on falls in elderly patients. A preplanned meta-analysis of the FICSIT Trials. Frailty and Injuries: Cooperative Studies of Intervention Techniques. JAMA 1995, 273(17):1341-1347

23. Sydenham E: Systematic reviews on preventing fall-related injuries in older people. Inj Prev 2008, 14(4):274.

24. Robertson MC, Campbell AJ, Gardner MM, Devlin N: Preventing injuries in older people by preventing falls: a meta-analysis of individual-level data. J Am Geriatr Soc 2002, 50(5):905-911.

25. Lyons RA, John A, Brophy S, Jones SJ, Johansen A, Kemp A, Lannon S, Patterson J, Rolfe B, Sander LV, et al: Modification of the home environment for the reduction of injuries. Cochrane Database Syst Rev 2006, 4:CD003600

26. Rapp K, Lamb SE, Erhardt-Beer L, Lindemann U, Rissmann U, Klenk J, Becker C: Effect of a statewide fall prevention program on incidence of 
femoral fractures in residents of long-term care facilities. $J$ Am Geriatr Soc 2010, 58(1):70-75.

27. Rubenstein LZ, Josephson KR, Robbins AS: Falls in the nursing home. Ann Intern Med 1994, 121(6):442-451.

28. Stevens JA, Corso PS, Finkelstein EA, Miller TR: The costs of fatal and nonfatal falls among older adults. Inj Prev 2006, 12(5):290-295.

29. Karlsson M: Does exercise reduce the burden of fractures? A review. Acta Orthop Scand 2002, 73(6):691-705.

30. Crowther M, Lim W, Crowther MA: Systematic review and meta-analysis methodology. Blood 2010, 116(17):3140-3146.

31. Hauer K, Lamb SE, Jorstad EC, Todd C, Becker C: Systematic review of definitions and methods of measuring falls in randomised controlled fall prevention trials. Age Ageing 2006, 35(1):5-10.

32. Cummings $P$, Koepsell TD, Mueller BA: Methodological challenges in injury epidemiology and injury prevention research. Annu Rev Public Health 1995, 16:381-400.

33. Butler $\mathrm{M}$, Kerse $\mathrm{N}$, Todd $\mathrm{M}$ : Circumstances and consequences of falls in residential care: the New Zealand story. N Z Med J 2004, 117(1202): U1076.

34. Haywood KL, Hargreaves J, White R, Lamb SE: Reviewing measures of outcome: reliability of data extraction. J Eval Clin Pract 2004, 10(2):329-337.

35. Bland JM: An Introduction to Medical Statistics. 3 edition. Oxford: Oxford University Press; 1995.

36. Campbell AJ, Robertson MC, Gardner MM, Norton RN, Tilyard MW, Buchner DM: Randomised controlled trial of a general practice programme of home based exercise to prevent falls in elderly women. BMJ 1997, 315(7115):1065-1069.

37. Elley CR, Robertson MC, Garrett S, Kerse NM, McKinlay E, Lawton B, Moriarty $H$, Moyes SA, Campbell AJ: Effectiveness of a falls-and-fracture nurse coordinator to reduce falls: a randomized, controlled trial of at-risk older adults. J Am Geriatr Soc 2008, 56(8):1383-1389.

38. Campbell AJ, Robertson MC, La Grow SJ, Kerse NM, Sanderson GF, Jacobs RJ, Sharp DM, Hale LA: Randomised controlled trial of prevention of falls in people aged $>$ or $=75$ with severe visual impairment: the VIP trial. BMJ 2005, 331(7520):817.

39. Robertson MC, Devlin N, Scuffham P, Gardner MM, Buchner DM, Campbell AJ: Economic evaluation of a community based exercise programme to prevent falls. J Epidemiol Community Health 2001, 55(8):600-606

40. Becker C, Kron M, Lindemann U, Sturm E, Eichner B, Walter-Jung B, Nikolaus T: Effectiveness of a multifaceted intervention on falls in nursing home residents. J Am Geriatr Soc 2003, 51(3):306-313.

41. Dyer CA, Taylor GJ, Reed M, Robertson DR, Harrington R: Falls prevention in residential care homes: a randomised controlled trial. Age Ageing 2004, 33(6):596-602.

42. Pfeifer M, Begerow B, Minne HW, Suppan K, Fahrleitner-Pammer A, Dobnig $\mathrm{H}$ : Effects of a long-term vitamin $\mathrm{D}$ and calcium supplementation on falls and parameters of muscle function in community-dwelling older individuals. Osteoporos Int 2009, 20(2):315-322.

43. Sanders KM, Stuart AL, Williamson EJ, Simpson JA, Kotowicz MA, Young D, Nicholson GC: Annual high-dose oral vitamin D and falls and fractures in older women: a randomized controlled trial. JAMA 2010, 303(18):1815-1822.

44. De Vries OJ, Peeters GMEE, Elders PJM, Muller M, Knol DL, Danner SA, Bouter LM, Lips P: Multifactorial intervention to reduce falls in older people at high risk of recurrent falls: A randomized controlled trial. Arch Intern Med 2010, 170(13):1110-1117.

45. Kemmler W, Von Stengel S, Engelke K, Haberle L, Kalender WA: Exercise effects on bone mineral density, falls, coronary risk factors, and health care costs in older women: The randomized controlled senior fitness and prevention (SEFIP) study. Arch Intern Med 2010, 170(2):179-185.

46. Jensen J, Lundin-Olsson L, Nyberg L, Gustafson Y: Fall and injury prevention in older people living in residential care facilities. A cluster randomized trial. Ann Intern Med 2002, 136(10):733-741.

47. Stenvall $M$, Olofsson B, Lundstrom M, Englund U, Borssen B, Svensson O, Nyberg L, Gustafson Y: A multidisciplinary, multifactorial intervention program reduces postoperative falls and injuries after femoral neck fracture. Osteoporos Int 2007, 18(2):167-175.
48. Reinsch S, MacRae P, Lachenbruch PA, Tobis JS: Attempts to prevent falls and injury: a prospective community study. Gerontologist 1992, 32(4):450-456

49. Lord SR, Tiedemann A, Chapman K, Munro B, Murray SM, Gerontology M, Ther GR, Sherrington C: The effect of an individualized fall prevention program on fall risk and falls in older people: a randomized, controlled trial. J Am Geriatr Soc 2005, 53(8):1296-1304.

50. Barnett A, Smith B, Lord SR, Williams M, Baumand A: Community-based group exercise improves balance and reduces falls in at-risk older people: a randomised controlled trial. Age Ageing 2003, 32(4):407-414.

51. Means KM, Rodell DE, O'Sullivan PS: Balance, mobility, and falls among community-dwelling elderly persons: effects of a rehabilitation exercise program. Am J Phys Med Rehabil 2005, 84(4):238-250.

52. Ray WA, Taylor JA, Brown AK, Gideon P, Hall K, Arbogast P, Meredith S: Prevention of fall-related injuries in long-term care: a randomized controlled trial of staff education. Arch Intern Med 2005, 165(19):2293-2298.

53. Ashburn A, Fazakarley L, Ballinger C, Pickering R, McLellan LD, Fitton C: $A$ randomised controlled trial of a home based exercise programme to reduce the risk of falling among people with Parkinson's disease. J Neurol Neurosurg Psychiatry 2007, 78(7):678-684.

54. Blalock SJ, Casteel C, Roth MT, Ferreri S, Demby KB, Shankar V: Impact of enhanced pharmacologic care on the prevention of falls: A randomized controlled trial. Am J Geriatr Pharmacother 2010, 8(5):428-440.

55. Haran MJ, Cameron ID, Ivers RQ, Simpson JM, Lee BB, Tanzer M, Porwal M Kwan MM, Severino C, Lord SR: Effect on falls of providing single lens distance vision glasses to multifocal glasses wearers: VISIBLE randomised controlled trial. BMJ (Clin Res Ed) 2010, 340:c2265.

56. Rizzo JA, Baker DI, McAvay G, Tinetti ME: The cost-effectiveness of a multifactorial targeted prevention program for falls among community elderly persons. Med Care 1996, 34(9):954-969.

57. Wolf SL, Barnhart HX, Kutner NG, McNeely E, Coogler C, Xu T: Reducing frailty and falls in older persons: an investigation of Tai Chi and computerized balance training. Atlanta FICSIT Group. Frailty and Injuries: Cooperative Studies of Intervention Techniques. J Am Geriatr Soc 1996, 44(5):489-497.

58. Ray WA, Taylor JA, Meador KG, Thapa PB, Brown AK, Kajihara HK, Davis C, Gideon P, Griffin MR: A randomized trial of a consultation service to reduce falls in nursing homes. JAMA 1997, 278(7):557-562.

59. Tinetti ME, Baker DI, McAvay G, Claus EB, Garrett P, Gottschalk M, Koch ML, Trainor K, Horwitz Rl: A multifactorial intervention to reduce the risk of falling among elderly people living in the community. N Engl J Med 1994, 331(13):821-827.

60. Campbell AJ, Robertson MC, Gardner MM, Norton RN, Buchner DM: Falls prevention over 2 years: a randomized controlled trial in women 80 years and older. Age Ageing 1999, 28(6):513-518.

61. Robertson MC, Devlin N, Gardner MM, Campbell AJ: Effectiveness and economic evaluation of a nurse delivered home exercise programme to prevent falls. 1: Randomised controlled trial. BMJ 2001, 322(7288):697-701.

62. Nikolaus T, Bach M: Preventing falls in community-dwelling frail older people using a home intervention team (HIT): results from the randomized Falls-HIT trial. J Am Geriatr Soc 2003, 51(3):300-305.

63. Kerse $\mathrm{N}$, Butler $\mathrm{M}$, Robinson $\mathrm{E}$, Todd $\mathrm{M}$ : Fall prevention in residential care: a cluster, randomized, controlled trial. J Am Geriatr Soc 2004, 52(4):524-531.

64. Hornbrook MC, Stevens VJ, Wingfield DJ, Hollis JF, Greenlick MR, Ory MG: Preventing falls among community-dwelling older persons: results from a randomized trial. Gerontologist 1994, 34(1):16-23.

65. Luukinen H, Lehtola S, Jokelainen J, Vaananen-Sainio R, Lotvonen S, Koistinen P: Pragmatic exercise-oriented prevention of falls among the elderly: a population-based, randomized, controlled trial. Prev Med 2007, 44(3):265-271.

66. Li F, Harmer P, Fisher K, McAuley E, Chaumeton N, Eckstrom E, Wilson NL: Tai Chi and fall reductions in older adults: a randomized controlled trial. J Gerontol A Biol Sci Med Sci 2005, 60(2):187-194.

67. Skelton D, Dinan S, Campbell M, Rutherford O: Tailored group exercise (Falls Management Exercise - FaME) reduces falls in community-dwelling older frequent fallers (an RCT). Age Ageing 2005, 34(6):636-639. 
68. Fitzharris MP, Day L, Lord SR, Gordon I, Fildes B: The Whitehorse NoFalls trial: Effects on fall rates and injurious fall rates. Age and Ageing 2010, 39(6):pp 728-pp 733.afq109.

69. Spice CL, Morotti W, George S, Dent THS, Rose J, Harris S, Gordon CJ: The Winchester falls project: A randomised controlled trial of secondary prevention of falls in older people. Age and Ageing 2009, 38(1):33-40.

70. Sihvonen S, Sipila S, Taskinen S, Era P: Fall incidence in frail older women after individualized visual feedback-based balance training. Gerontology 2004, 50(6):411-416.

71. Salminen $M$, Vahlberg $T$, Kivela SL: The long-term effect of a multifactorial fall prevention programme on the incidence of falls requiring medical treatment. Publ Health 2009, 123(12):809-813.

72. Wolf SL, Sattin RW, Kutner M, O'Grady M, Greenspan Al, Gregor RJ: Intense tai chi exercise training and fall occurrences in older, transitionally frail adults: a randomized, controlled trial. J Am Geriatr Soc 2003, 51(12):1693-1701.

73. Hendriks MR, Bleijlevens MH, van Haastregt JC, Crebolder HF, Diederiks JP, Evers SM, Mulder WJ, Kempen Gl, van Rossum E, Ruijgrok JM, et al: Lack of effectiveness of a multidisciplinary fall-prevention program in elderly people at risk: a randomized, controlled trial. J Am Geriatr Soc 2008, 56(8):1390-1397.

74. Karkkainen MK, Tuppurainen M, Salovaara K, Sandini L, Rikkonen T, Sirola J, Honkanen R, Arokoski J, Alhava E, Kroger H: Does daily vitamin D 800 IU and calcium $1000 \mathrm{mg}$ supplementation decrease the risk of falling in ambulatory women aged 65-71 years? A 3-year randomized populationbased trial (OSTPRE-FPS). Maturitas 2010, 65(4):359-365.

75. Suman S, Myint PK, Clark A, Das P, Ring L, Trepte NJB: Community-based fall assessment compared with hospital-based assessment in community-dwelling older people over 65 at high risk of falling: A randomized study. Aging - Clin Exp Res 2011, 23(1):35-41.

76. Vind $A B$, Andersen $H E$, Pedersen $K D$, Jorgensen $T$, Schwarz P: An outpatient multifactorial falls prevention intervention does not reduce falls in Highrisk elderly danes. J Am Geriatr Soc 2009, 57(6):971-977.

77. Association for the Advancement of Automotive Medicine, Committee on Injury Scaling: The Abbreviated Injury Scale-1990 Revision (AIS-90). Des Plains, IL: Association for the Advancement of Automotive Medicine; 1990

78. Buchner DM, Hornbrook MC, Kutner NG, Tinetti ME, Ory MG, Mulrow CD, Schechtman KB, Gerety MB, Fiatarone MA, Wolf SL, et al: Development of the common data base for the FICSIT trials. J Am Geriatr Soc 1993 41(3):297-308.

79. Cummings SR, Nevitt MC, Kidd S: Forgetting falls. The limited accuracy of recall of falls in the elderly. J Am Geriatr Soc 1988, 36(7):613-616.

80. Nevitt MC, Cummings SR, Browner WS, Seeley DG, Cauley JA, Vogt TM, Black DM: The accuracy of self-report of fractures in elderly women: evidence from a prospective study. Am J Epidemiol 1992, 135(5):490-499.

81. Alexandrescu R, O'Brien SJ, Lecky FE: A review of injury epidemiology in the UK and Europe: some methodological considerations in constructing rates. BMC Publ Health 2009, 9:226.

82. Gregg EW, Cauley JA, Seeley DG, Ensrud KE, Bauer DC: Physical activity and osteoporotic fracture risk in older women. Study of Osteoporotic Fractures Research Group. Ann Intern Med 1998, 129(2):81-88.

83. Cumming RG, Nevitt MC, Cummings SR: Epidemiology of hip fractures. Epidemiol Rev 1997, 19(2):244-257.

84. MacKenzie EJ, Shapiro S, Eastham JN: The Abbreviated Injury Scale and Injury Severity Score. Levels of inter- and intrarater reliability. Med Care 1985, 23(6):823-835.

\section{Pre-publication history}

The pre-publication history for this paper can be accessed here: http://www.biomedcentral.com/1471-2288/12/50/prepub

doi:10.1186/1471-2288-12-50

Cite this article as: Schwenk et al: Definitions and methods of measuring and reporting on injurious falls in randomised controlled fall prevention trials: a systematic review. BMC Medical Research Methodology 2012 12:50.

\section{Submit your next manuscript to BioMed Central and take full advantage of:}

- Convenient online submission

- Thorough peer review

- No space constraints or color figure charges

- Immediate publication on acceptance

- Inclusion in PubMed, CAS, Scopus and Google Scholar

- Research which is freely available for redistribution

Submit your manuscript at www.biomedcentral.com/submit 